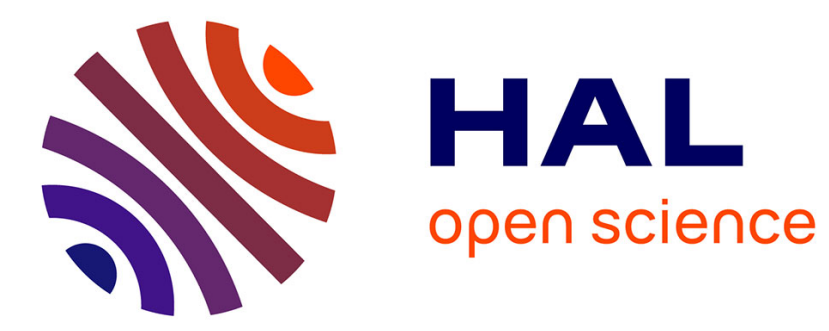

\title{
Simulations and measurements of optical images of insonified ultrasound contrast microbubbles
}

\author{
Michiel Postema, Ayache Bouakaz, Chien Ting Chin, Nico de Jong
}

\section{To cite this version:}

Michiel Postema, Ayache Bouakaz, Chien Ting Chin, Nico de Jong. Simulations and measurements of optical images of insonified ultrasound contrast microbubbles. IEEE Transactions on Ultrasonics, Ferroelectrics and Frequency Control, 2003, 50 (5), pp.523-536. 10.1109/TUFFC.2003.1201465 . hal03193417

\section{HAL Id: hal-03193417 https://hal.science/hal-03193417}

Submitted on 13 Apr 2021

HAL is a multi-disciplinary open access archive for the deposit and dissemination of scientific research documents, whether they are published or not. The documents may come from teaching and research institutions in France or abroad, or from public or private research centers.
L'archive ouverte pluridisciplinaire HAL, est destinée au dépôt et à la diffusion de documents scientifiques de niveau recherche, publiés ou non, émanant des établissements d'enseignement et de recherche français ou étrangers, des laboratoires publics ou privés. 


\title{
Simulations and Measurements of Optical Images of Insonified Ultrasound Contrast Microbubbles
}

\author{
Michiel Postema, Member, IEEE, Ayache Bouakaz, Chien Ting Chin, \\ Nico de Jong, Associate Member, IEEE
}

\begin{abstract}
Ultrasound contrast agents (UCAs) are used in a clinical setting to enhance the backscattered signal from the blood pool to estimate perfusion and blood flow. The UCAs consist of encapsulated microbubbles, measuring $1-10 \mu \mathrm{m}$ in diameter. Acoustic characterization of UCAs is generally carried out from an ensemble of bubbles. The measured signal is a complicated summation of all signals from the individual microbubbles. Hence, characterization of a single bubble from acoustic measurements is complex.

In this study, 583 optical observations of freely flowing, oscillating, individual microbubbles from an experimental UCA were analyzed. The excursions during ultrasound exposure were observed through a microscope. Images were recorded with a high frame rate camera operating at $3 \mathrm{MHz}$. Microbubbles on these images were measured off-line and maximal excursions were determined. A technique is described to determine the diameters of the bubbles observed. We compared the maximal excursions of microbubbles of the same initial size in an ultrasound field with a $500 \mathrm{kHz}$ center frequency at acoustic amplitudes ranging from $0.06 \mathrm{MPa}$ to $0.85 \mathrm{MPa}$.

It was concluded that maximal excursions of identical bubbles can differ by $150 \%$ at low acoustic pressures (mechanical index or $\mathrm{MI}<0.2)$. At a high acoustic pressure $(\mathrm{MI}=1.2)$ an image sequence was recorded on which a bubble collapsed, while an apparently identical bubble survived.
\end{abstract}

This work has been supported by the Technology Foundation STW (RKG.5104).

The authors are with the Department of Experimental Echocardiography, Thoraxcenter, Erasmus MC-University Medical Center, Rotterdam, The Netherlands (e-mail: m.postema@erasmusmc.nl).

M. Postema, A. Bouakaz, and N. de Jong are also with the Interuniversity Cardiology Institute of The Netherlands (ICIN), Utrecht, The Netherlands.

C. T. Chin is also with the Foundation for Fundamental Research on Matter (FOM), Utrecht, The Netherlands. 


\section{INTRODUCTION}

Detecting perfusion and blood flow is of great clinical interest, but technically challenging, because blood reflects ultrasound poorly. Reflections from blood can be increased by administering gaseous bubbles, due to their high echogenicity. Microbubble-based ultrasound contrast agents (UCAs) make blood better detectable in B-mode and Doppler mode imaging [1], [2], [3]. A wide variety of contrast agents is commercially available or under clinical trial and development [1]. De Jong \& Ten Cate [4] gave an overview of clinical applications and technological innovations of ultrasound contrast agents. A review of current and near future detection procedures of UCAs was written in [5].

Most of the commercially available UCAs consist of encapsulated microbubbles of low solubility gas, measuring $1-10 \mu \mathrm{m}$ in diameter. They are sufficiently stable to pass into the systemic circulation following injection into a peripheral vein. Nowadays, new generations of UCA are under investigation to further improve the scattering from blood and to ameliorate its detection in the presence of surrounding tissue. In addition to UCA design and development, increased interest is directed to the development of more sensitive ultrasound equipment to visualize UCA. Consequently, contrast echocardiography has become a rapidly evolving field encompassing a family of technologies and practices for the noninvasive assessment of cardiac structure and function. Recent developments in engineering of microbubbles and in adapted imaging systems such as triggered modality in combination with imaging techniques such as power Doppler, pulse inversion and power modulation imaging are facilitating simultaneous assessment of myocardial function and perfusion [1], [6]. Despite these new imaging techniques, myocardial contrast echocardiography has to overcome several problems if it is to be able to quantify myocardial blood flow. These limitations can be surmounted with a better understanding of the behavior of a single microbubble in an ultrasound field. As a matter of fact, the interactions of microbubbles with an ultrasound beam are complex. When a microbubble is exposed to an oscillating acoustic signal, it undergoes alternate expansions and contractions, equal and symmetrical at low acoustic powers, i.e., mechanical index $(\mathrm{MI})<0.1$. The mechanical index is defined as $\mathrm{MI}=\frac{\mathrm{P}^{-}}{\sqrt{\mathrm{F}}}$, where $\mathrm{P}^{-}$the peak negative acoustic pressure in megapascals (MPa) and $\mathrm{F}$ is the center frequency of the ultrasound in megahertz $(\mathrm{MHz})$. As the acoustic power increases, more complex nonlinear interactions occur. This oscillating behavior is associated with the production of harmonic signals. At still higher powers, highly nonlinear behavior is associated with complex bubble behavior, which can be revealed by phenomena like bubble rupture, fragmentation, and merging.

An improved understanding of contrast bubble properties and behavior under the influence of ultrasound may lead to more sophisticated detection techniques. Until now, mostly ultrasonic measurements supported 
by theoretical models were adopted to elucidate and quantify the interaction between ultrasound beam and contrast gas bubbles [7], [8], [9], [10], [11]. The experiments were mostly performed on an ensemble of gas bubbles with certainly a range of different sizes and possibly different shell parameters. Therefore, these studies express a bulk response of a majority of bubbles. Hence, the behavior and contribution of individual bubbles becomes difficult to predict. To make more thorough investigations on individual bubble response to ultrasound excitation, and by that develop new detection techniques, optical visualization of oscillating bubbles represents an attractive alternative. Over the past years various studies were performed involving visualization of gas bubbles during ultrasound irradiation. Klibanov et al. [12] observed oscillations of UCA bubbles attached to a Petri dish with a 30 frames per second camera. Dayton et al. [13], [14] combined acoustical observations of UCA and optical observations with a 600 frames per second camera. They observed gas release and bubble destruction. Takeuchi [15], [16] used TV-frame synchronous illumination and insonification to observe microballoon breakage. Because of the low frame rates of the cameras mentioned, the instance of shell breakage and the behavior of a bubble within an ultrasound cycle could not be observed. Kuribayashi et al. [17] observed changes in UCA bubble diameters within one cycle of ultrasound, at frame rates up to $10 \mathrm{MHz}$ and $50 \times$ magnification. They concluded that the imaging frame rate and magnification were not sufficient for studying the details of UCA bubble behavior. De Jong et al. [18] carried out a preliminary study on this subject. They proposed a method to visualize the oscillations of bubbles using a microscope and a fast framing camera operating at a $4 \mathrm{MHz}$ frame rate. Furthermore, they compared radius-time curves, derived from two-dimensional bubble pictures, to a theoretical model. Morgan et al. [19] used a 100 megaframes per second camera in streak mode to predict bubble-oscillating behavior.

In this study, 583 optical observations of freely flowing, oscillating, individual microbubbles from an experimental UCA were analyzed. The excursions during ultrasound exposure were observed through a microscope. Images were recorded with a high frame rate camera operating at $3 \mathrm{MHz}$. Microbubbles on these images were measured off-line and maximal excursions were determined. A technique is described to precisely determine the diameters of the bubbles observed. We compared the maximal excursions of microbubbles of the same initial size in an ultrasound field with a $500 \mathrm{kHz}$ frequency at acoustic amplitudes ranging from $0.06 \mathrm{MPa}$ to $0.85 \mathrm{MPa}$. Furthermore, examples are shown of two-dimensional observations, revealing bubble-collapse and bubbles merging. In addition, the results are compared to theory. 


\section{OPTICAL IMAGING THEORY AND SIMULATIONS}

The optical system was studied to determine the relation between observed bubble sizes and true bubble sizes. To measure a bubble from an optical image, it has to be segmented from the background of the image. The measurement depends on the characteristics of the optical system and on the segmentation technique applied. In this section a segmentation technique is applied to simulated images to estimate the precision of our optical system.

An optical image of a radially symmetric flat object in focus, observed through a microscope, can be expressed as the following illumination intensity function:

$$
g(r)=\int_{-\infty}^{\infty} \operatorname{PSF}(r-\gamma) f(\gamma) \mathrm{d} \gamma+\eta(r)
$$

where $r$ is the coordinate in the image plane, $\gamma$ is the coordinate in the object plane, $g$ is the intensity of the image observed, PSF is the point-spread function of the optical imaging system, $f$ represents the illumination intensity of the object, and $\eta$ is a one-dimensional additive noise function [20], [21]. The PSF, derived from geometrical optics, is given by [22], [23]:

$$
\operatorname{PSF}(r)=\left(2 \frac{J_{1}(a r)}{a r}\right)^{2}, \quad a=\frac{2 \pi N A}{\lambda},
$$

where $J_{1}$ is the first-order Bessel function of the first kind, NA is the numerical aperture of the objective lens, and $\lambda$ is the wavelength of the light. The PSF of our optical system was computed for $N A=1.25$ and $\lambda=500 \mathrm{~nm}$. The resolution $\mathcal{R}$ of an optical system is defined by the Rayleigh criterion [24] $\operatorname{PSF}\left(\frac{1}{2} \mathcal{R}\right)=0$, which holds for $\mathcal{R}=1.22 \frac{\lambda}{\mathrm{NA}}$.

To simulate the imaging in focus, we defined five differently sized circularly symmetric objects $f$ : the Heaviside function $f(r)=\left\{\begin{array}{c}1, \quad r \geq 0 \\ 0, \quad r<0\end{array}\right.$, and four disks with diameters $\tau$ of $1 \mu \mathrm{m}, 0.5 \mu \mathrm{m}, 0.2 \mu \mathrm{m}$, and $0.1 \mu \mathrm{m}$, respectively. $\tau_{i}$ corresponds to the true diameter of disk $i$. By applying (1) to $f$ and assuming $\eta=0$, simulated images $g$ were obtained [Figure 1]. To obtain the true object diameters from the obtained images, the objects had to be segmented. A common method to discriminate objects from the background in optical images is to segment the image into:

$$
\xi(r)= \begin{cases}1, & g(r) \leq \theta \\ 0, & g(r)>\theta\end{cases}
$$

where $\xi$ represents the segmented image and $\theta$ is the gray-level used as a threshold value; (3) segments objects that are lighter than the background. This segmentation technique is called gray-level windowslicing [21]. Window-slicing was applied to the images $g$ in Figure 1 . A threshold value $\theta=0.5$ was used for segmentation, corresponding to a threshold level halfway between imaged object intensity $g=1$ 


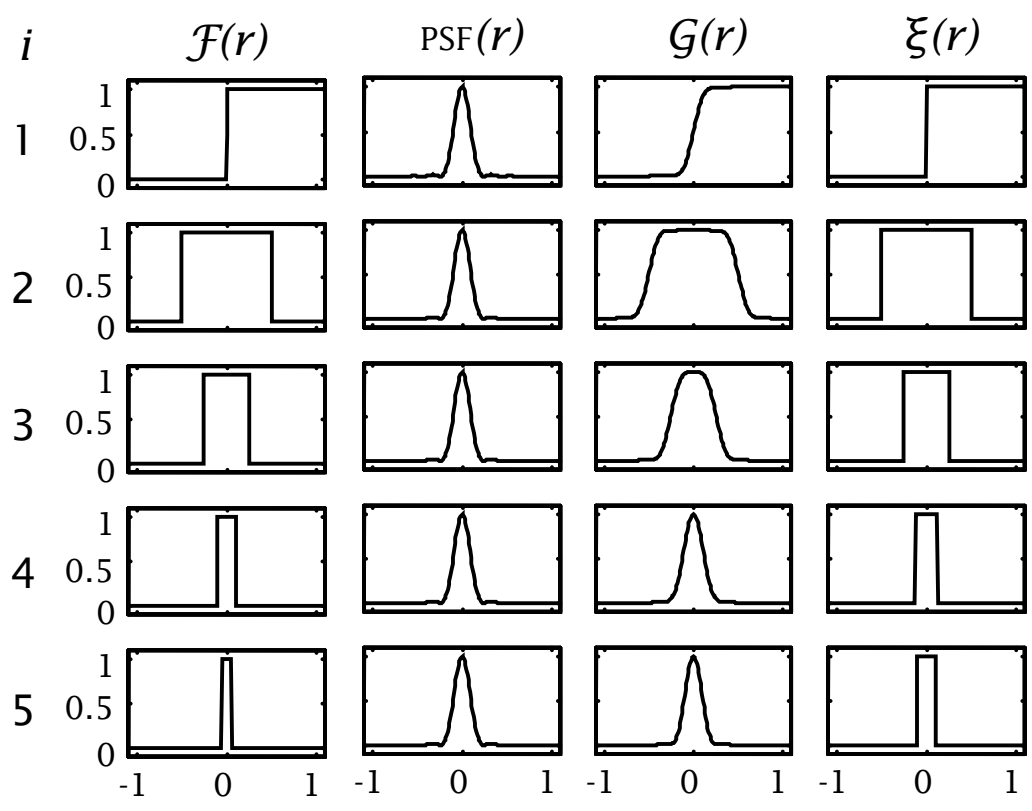

Figure 1: One-dimensional, differently sized objects $f$, convolved with the PSF, resulting in optical images $g$. Segmented objects $\xi$ were obtained after applying the threshold $\theta=0.5$.

and background $g=0$. The segmented values $\xi$ are plotted as a function of lateral distance $r$. We define $\zeta_{i}$ as the diameter of a segmented object in image $i$. We show in Table I that $\zeta_{i}$ corresponds to the true object diameter $\tau_{i}$, except for objects $i=4$ and $i=5$. The disk sized $\tau_{5}$ is too narrow to be detected with a threshold of $50 \%$ between object intensity and background under conditions similar to those of our optical system. For disks in the size range $50 \mathrm{~nm} \leq \tau \leq 2 \mu \mathrm{m}$, simulated images $g(r)$ were calculated. The previously described $50 \%$ threshold $\theta=0.5$ was applied for segmentation. The resulting measured diameters $\zeta$ were plotted as a function of $\tau$ [Figure 2]. For $\tau>0.35 \mu \mathrm{m}$, the measured object diameter was equal to the true object diameter $(\zeta=\tau)$. Thus, true object diameters larger than $0.35 \mu \mathrm{m}$ can be determined from one-dimensional, gray-scaled, monochromic optical images with a 50\% threshold between object intensity and image background. For objects smaller than $\oslash 0.35 \mu \mathrm{m}$, the measured diameters deviate from the true diameters and approach half of the resolution $\mathcal{R}$ of the optical system.

We investigated the influence of the threshold value on the measured diameters. Figure 3 shows the measured diameter $\zeta$ as a function of applied threshold $\theta$ for three differently sized disks. The slopes of 


\begin{tabular}{|c|c|c|}
\hline $\begin{array}{l}\text { Object } \\
\quad i\end{array}$ & $\begin{array}{l}\text { Object diameter } \\
\tau(\mu \mathrm{m})\end{array}$ & $\begin{array}{c}\text { Segmented object } \\
\text { diameter } \\
\zeta(\mu \mathrm{m})\end{array}$ \\
\hline 1 & $\infty$ & $\infty$ \\
\hline 2 & 1.0 & 1.0 \\
\hline 3 & 0.50 & 0.50 \\
\hline 4 & 0.20 & 0.24 \\
\hline 5 & 0.10 & 0.22 \\
\hline
\end{tabular}

Table I: True and segmented object diameter.

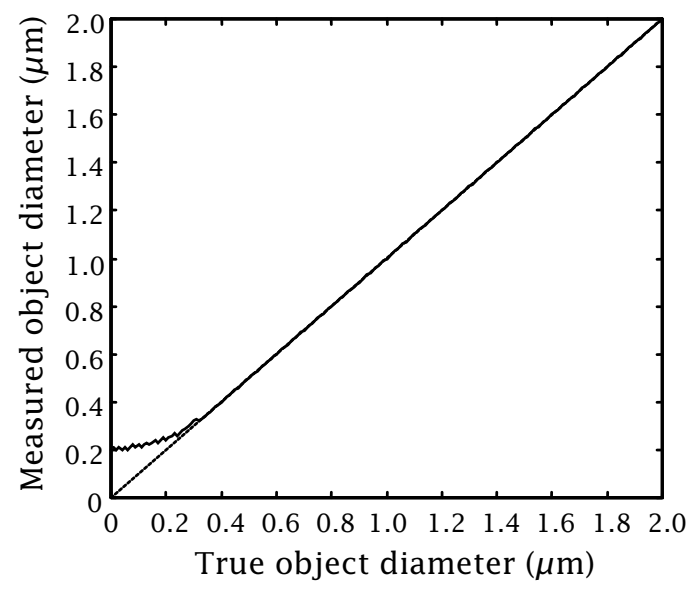

Figure 2: Measured object diameter $(\zeta)$ versus true object diameter $(\tau)$ after segmentation using the threshold $\theta=0.5$.

the curves are determined by the PSF. For thresholds $0.3 \leq \theta \leq 0.7$, measured diameter $\zeta$ equals true diameter $\tau \pm 0.1 \mu \mathrm{m}$, which means that flat object diameters can be determined with $0.1 \mu \mathrm{m}$ precision. The effects of defocusing have been mathematically described by [25], [26], [27], [28]. When an object is large compared to the PSF, only the slope of the edge is changed by defocusing. Hence, the threshold $\theta=0.5$ is still applicable [29]. A three-dimensional object can be considered as a stack of infinitely thin two-dimensional layers [20], [30], [31]. When three-dimensional objects are imaged through a microscope, the image projected onto the charge coupled device (CCD) element consists of contributions from all 


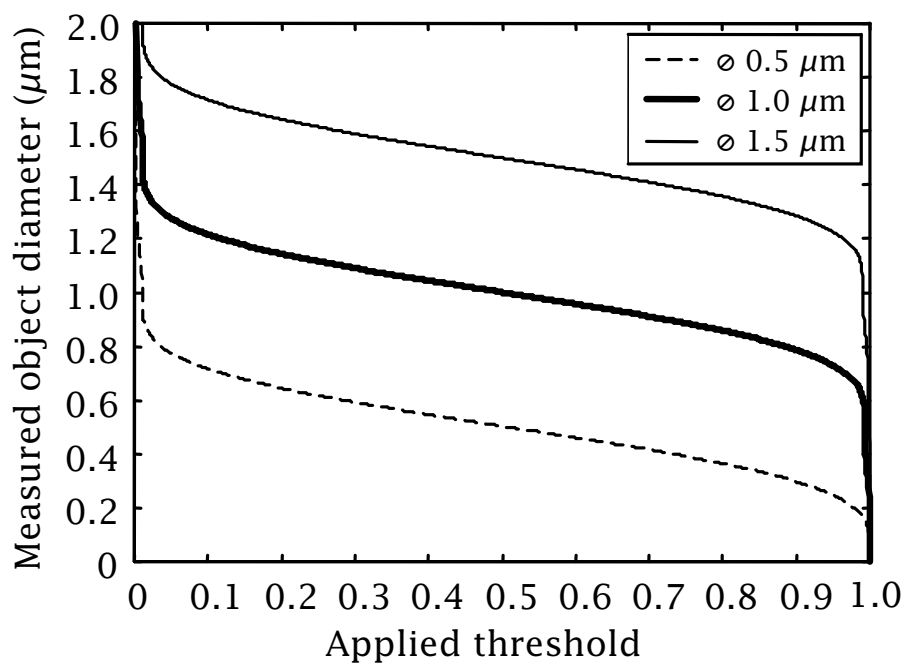

Figure 3: Measured object diameter $(\zeta)$ as a function of applied threshold $(\theta)$ for three different object diameters.

layers. A sphere is considered in focus when the middle layer of the sphere is in the focal plane [28], [31]. Bubbles which are large compared to the resolution have to be considered as part of the optical system [32]. Hence, images from an axial shift above the focal plane are not necessarily identical to the images from the same shift below the focal plane.

\section{MAterials AND Methods}

An overview of the experimental setup for taking pictures of oscillating contrast agent microbubbles is shown in Figure 4. A computer controlled the triggering of a waveform generator, a Xenon flash source, and a fast framing camera. The electrical signal generated by the LW 420A waveform generator (LeCroy Corp., Chestnut Ridge, NY), typically consisting of 10 cycles at $500 \mathrm{kHz}$, was adjusted by two variable 355C/D attenuators (Hewlett Packard Company, Palo Alto, CA) in series, and an A-500 $60 \mathrm{~dB}$ linear power amplifier (ENI technology, Inc., Rochester, NY). It was converted to ultrasound by a V389SU $500 \mathrm{kHz}$ single-element transducer (Panametrics Inc., Waltham, MA), spherically focused at $7.5 \mathrm{~cm}$. The transducer was mounted in a Perspex container at an angle of $45^{\circ}$ relative to the lid of the container, as shown in Figure 5. This container was filled with saturated water. A $\oslash 200 \mu \mathrm{m}$ cellulose Cuprophan ${ }^{\circledR}$ capillary tube (Membrana GmbH, Wuppertal, Germany) was fixed in the focal area of the transducer, through which contrast agent was flowing. Because the wall of the capillary tube had been impregnated 


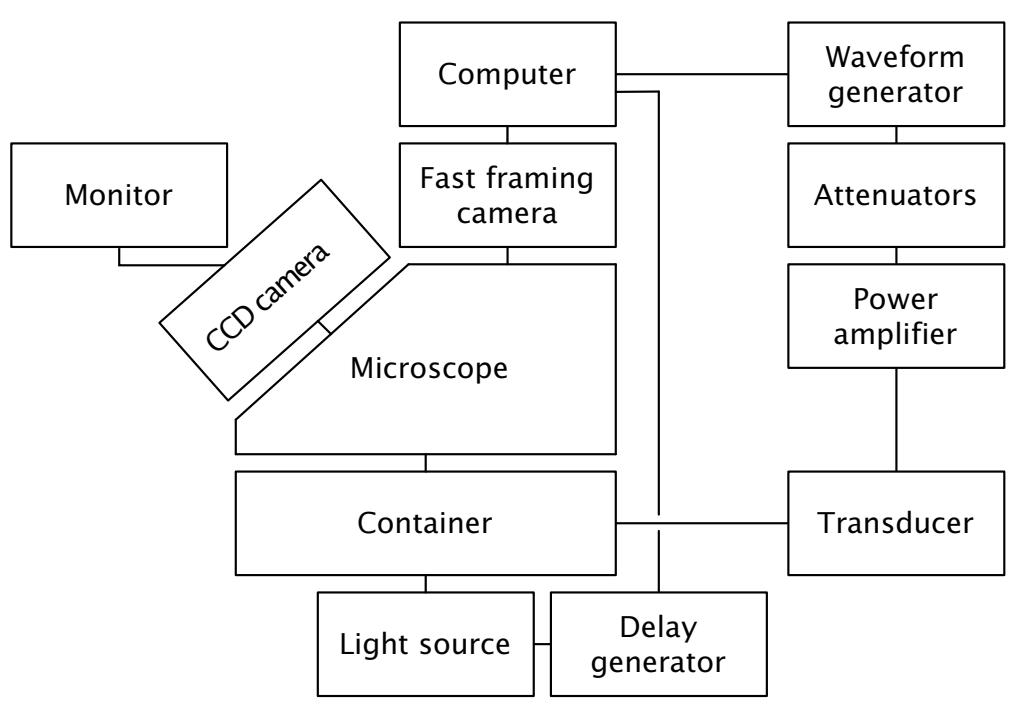

Figure 4: Basic setup for taking UCA microbubble pictures.

with water and because the tube was much smaller in diameter than the acoustic wavelenght, it was not expected to interfere with the ultrasound transmitted. Without contrast agent inserted, we did not observe reflections from the tube. Underneath the capillary tube either a $\oslash 5 \mathrm{~mm}$ or a $\oslash 7 \mathrm{~mm}$ optic fiber was fixed, that was mounted to a modified Xenon flash source. This light source was triggered by a PM 5716 pulse/delay generator (Koninklijke Philips Electronics N.V., Eindhoven, The Netherlands).

The container was positioned beneath a BH-2 microscope (Olympus Optical Co., Ltd., Tokyo, Japan) with an SPlan 100 oil immersion objective lens (Olympus Optical Co., Ltd.) with numerical aperture NA = 1.25. Because we did not use oil but water between the objective lens and the capillary tube, the numerical aperture was reduced to $N A_{\mathrm{w}}=\frac{n_{\mathrm{w}}}{n_{\mathrm{oil}}} N A=\frac{1.3}{1.5} \cdot 1.25=1.1$, where $N A_{\mathrm{w}}$ is the reduced numerical aperture, $n_{\mathrm{w}}$ is the refraction index of water, and $n_{\mathrm{oil}}$ is the refraction index of oil. Because the reduced numerical aperture is much higher than 0.6, our optical system still could be considered a high-NA imaging system [33]. For focusing and calibration purposes, a WAT-902HS CCD camera (Watec Co., Ltd., Yamagata, Japan) was fitted to the eye-piece of the microscope. Focusing was done manualy at the middle of the cellulose tube. Because the tube was wide compared to the contrast microbubbles measured, its upper half was considered a flat surface between contrast microbubbles and object lens, not causing aberrations but theoretically lowering the dynamic range of the images. The optical observations were recorded 


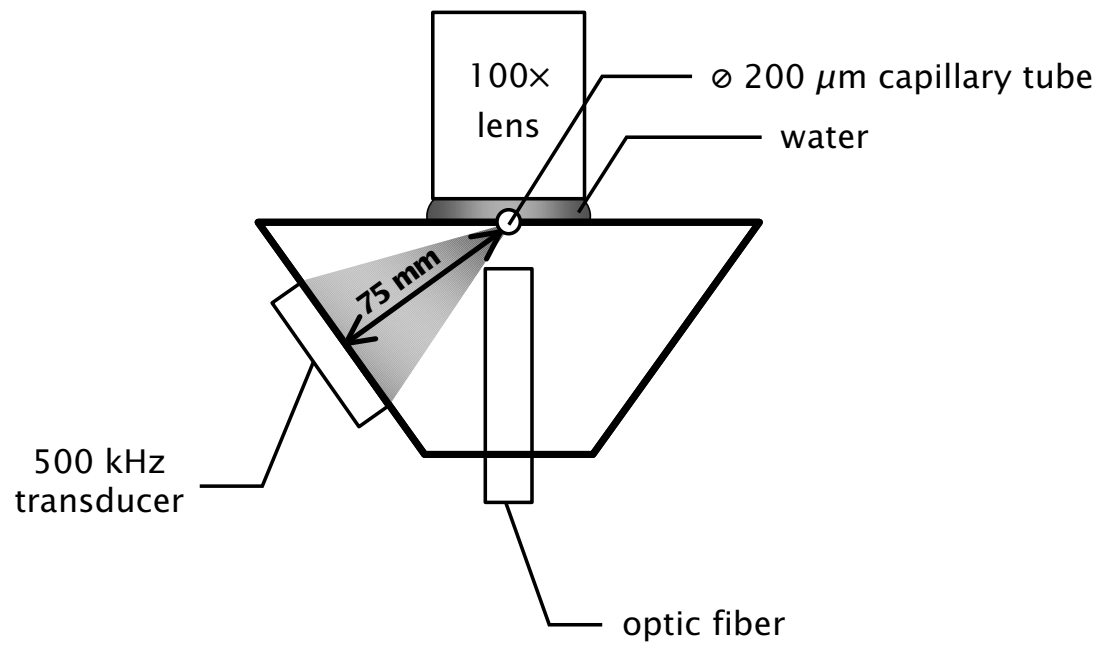

Figure 5: Front-side view of container.

with an Imacon 468 fast framing camera (DRS Hadland, Ltd., Tring, UK), capable of recording eight two-dimensional frames at $100 \mathrm{MHz}$. In all observations, the first frame was taken a few microseconds before ultrasound waves reached the contrast agent. The other seven frames were taken during ultrasound insonification, with $330 \mathrm{~ns}$ interframe time for $500 \mathrm{kHz}$ ultrasound, spanning a full ultrasound cycle. Frame exposure times ranged from $10 \mathrm{~ns}$ to $70 \mathrm{~ns}$. A photograph of the optical observation part of the setup is shown in Figure 6.

We investigated an experimental UCA (supplied by Bracco Research SA, Geneva, Switzerland). It consists of phospholipid-encapsulated gas bubbles ranging in diameter from 1 to $6 \mu \mathrm{m}$ with a median of $2 \mu \mathrm{m}$. The acoustic behavior of a very similar contrast agent was modeled and described in [34]. In this article we make use of the parameters from this model. The UCA bubbles were insonified by $500 \mathrm{kHz}$ ultrasound at peak negative acoustic pressures between 0.06 and $0.85 \mathrm{MPa}$. Acoustic pressures applied were measured with a calibrated MH28-10 hydrophone (FORCE Technology, Brøndby, Denmark) in a separate water tank. Figure 7 displays the acoustic signal measured at the transducer focus, after 


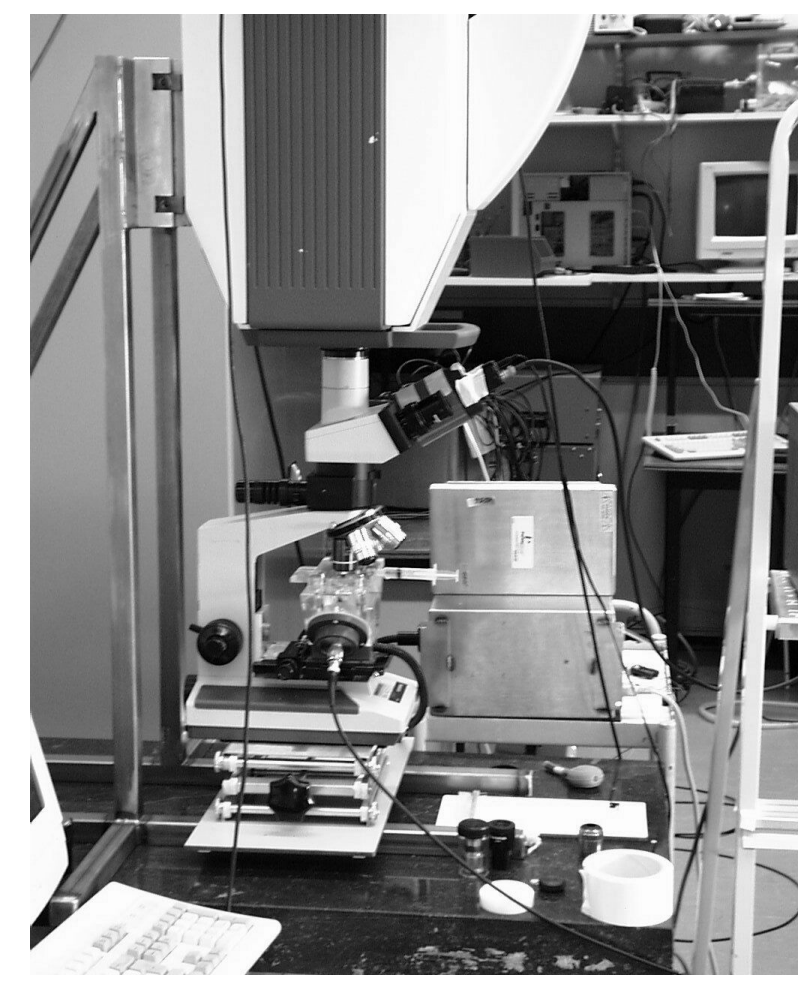

Figure 6: Optical observation part of the experimental setup.

transmitting 10 cycles of ultrasound at $210 \mathrm{kPa}$ peak negative pressure. It is assumed the in-situ acoustic signal is comparable to the signal measured.

Undiluted UCA ( $5 \mathrm{ml}$ of a $0.9 \%$ sodium chloride dilution, added to a $25 \mathrm{mg}$ UCA vial) was inserted through the capillary tube using either a syringe pressed by hand or a hose operated by a gravity fed or pumped infusion.

Furthermore, we did observations of diluted Quantison ${ }^{\mathrm{TM}}$ (Upperton Limited, Nottingham, UK) UCA, freely flowing underneath a glass coverslip.

The measuring of the numerous experimental UCA microbubbles was done with a partly automated method, using a MATLAB ${ }^{\circledR}$ (The MathWorks, Inc., Natick, MA) program. From previously recorded images, bubbles were selected for off-line measurement. These bubbles were selected only if they were visibly sharp, both before ultrasound arrival and in maximal expansion phase. Around each bubble to be measured, a rectangular region of interest was selected manually, which was much larger than the bubble 


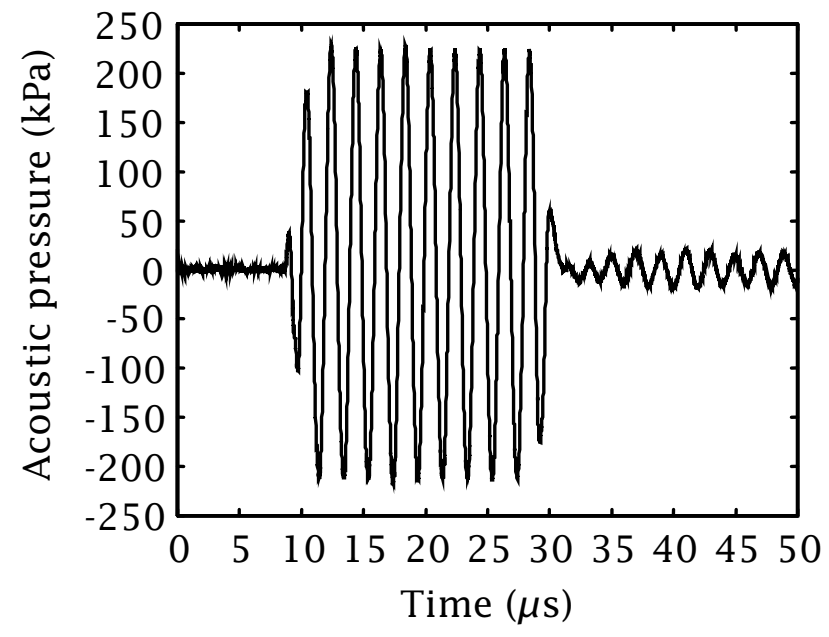

Figure 7: Acoustic signal measured at the transducer focus.

[Figure 8(a) and (b)]. The background level $\psi$ of the region of interest was determined automatically by calculating the median gray-value of the region of interest. The darkest value $\phi$ inside the region of interest was taken automatically as representative for the bubble wall. Segmentation was done by automatically applying the $50 \%$ threshold

$$
\theta=\frac{1}{2}(\phi+\psi)
$$

to the selected region of interest of the image [Figure 8(c)]. Due to nonuniform illumination and dark spots outside the bubble wall, the segmented bubble would sometimes not be represented by a circular shape. In those cases the threshold was set manually to a value typical for the particular region of interest. If the resulting image did not appear to have a continuous circular shape, the measurement would not be taken into account. Individual circular areas were selected manually to be measured. Segmented points outside a selected circular area were removed automatically and the area inside the circular area was filled automatically [Figure 8(d)]. The bubble area $A$ was measured by summation of all points of the circular area [22], [35]. Bubble diameters $d$ were calculated with the equation $d=2 \sqrt{\frac{A}{\pi}}$. 

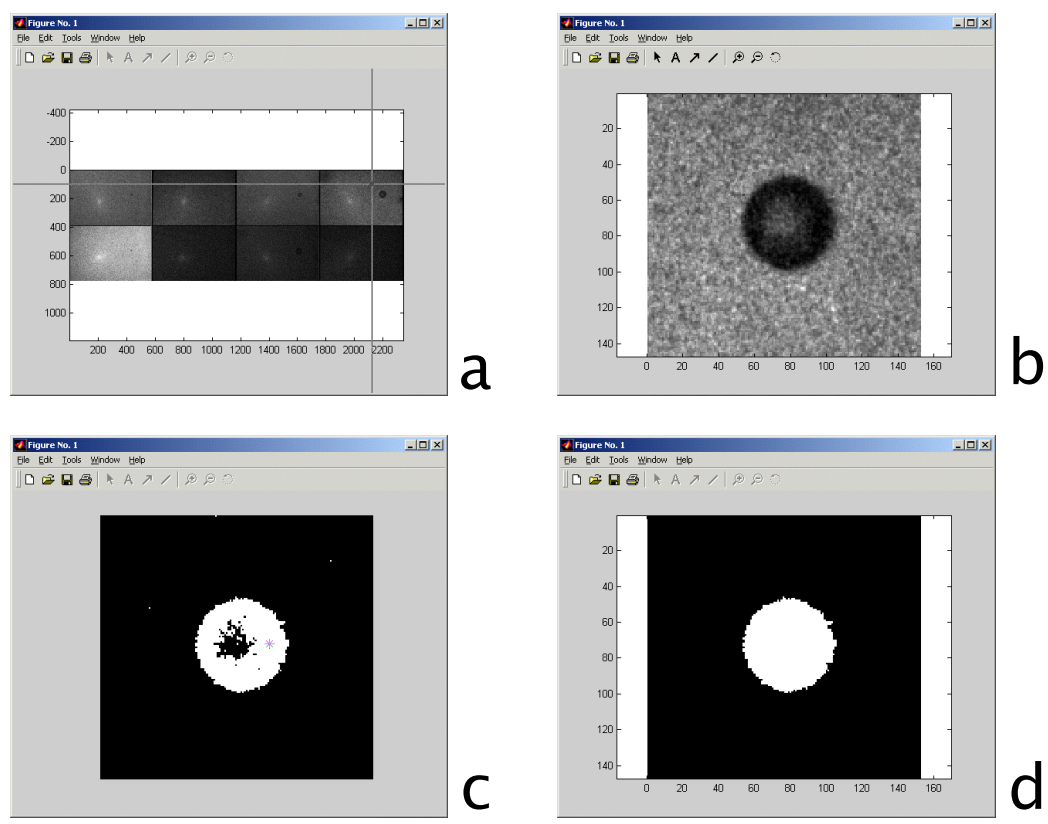

Figure 8: Semi-automated segmentation. Selection of region of interest (a) and (b), binary segmented image (c), segmented object $(d)$.

\section{RESULTS}

\section{Object size measurements}

To perform measurements on flat, circular objects, a test grid was built (DIMES/TU Delft, Delft, The Netherlands). It consists of differently sized transparent triacontakaidigons (32-sided polygons) on a dark background, each specified by the diameter of the biggest circle fitting inside the triacontakaidigon. From measurements of a 228.0 cycles/mm grid on a negative 1951 USAF glass slide resolution target (Edmund Industrial Optics, Barrington, NJ) [36] it was appreciated that identical transparent and dark objects were measured the same width. Hence, the results of measurements of transparent triacontakaidigons on a dark background are expected to be the same as those of measurements of dark triacontakaidigons on a transparent background. Figure 9(i) shows two 8-bit optical images of the test grid, recorded with the WAT-902HS CCD camera (Watec Co., Ltd.). The image size corresponds to a $43 \times 32 \mu \mathrm{m}^{2}$ area. The median intensity $\phi$ inside triacontakaidigon 1 was $\phi=187$ and the median background value $\psi$ was $\psi=28$, giving a $50 \%$ threshold level of $\theta=1 / 2(\phi+\psi)=107.5$. This threshold was applied to both images [Figure 9(ii)]. From the measured areas, the respective diameters were calculated and corrected 


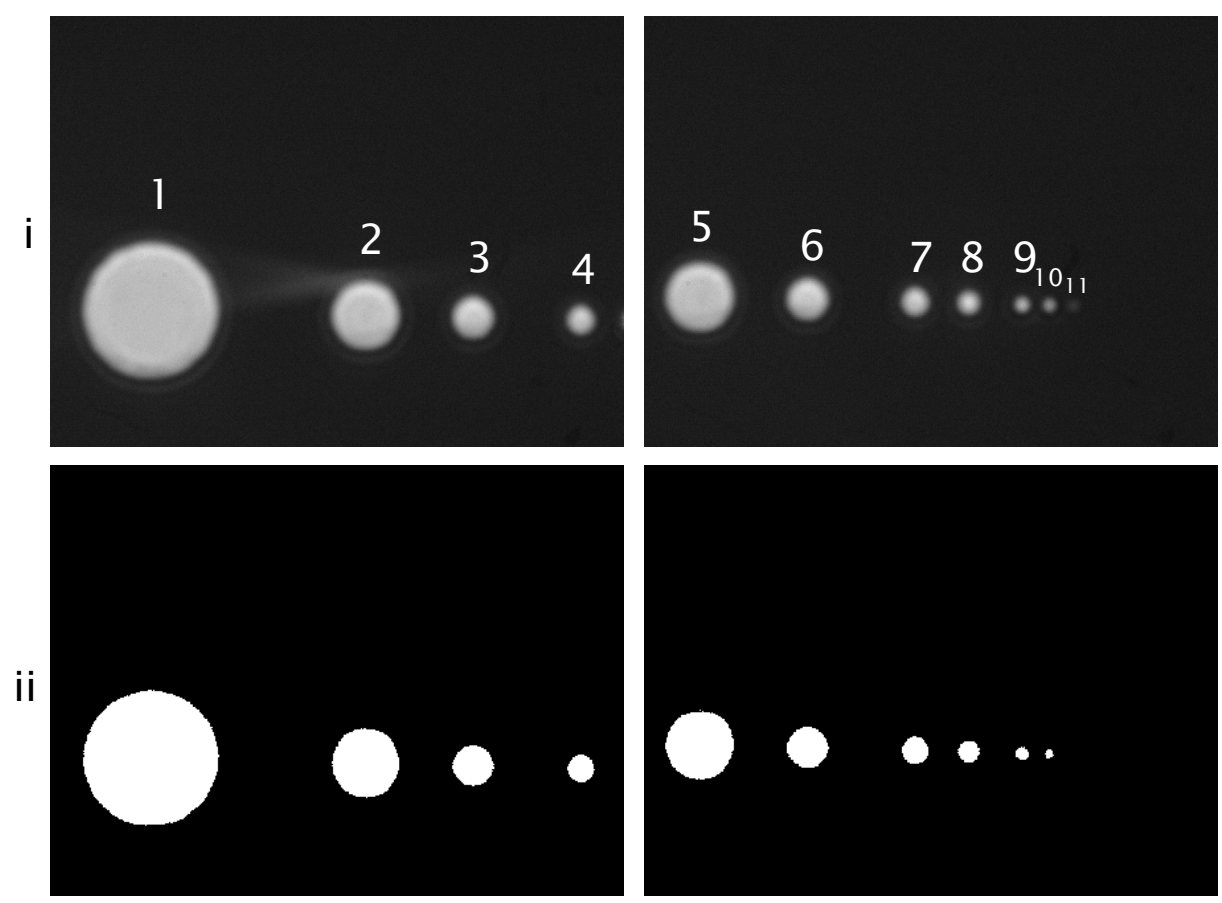

Figure 9: CCD images of 11 triacontakaidigons (i) on a calibration grid, (ii) segmented with a $\theta=1 / 2(\phi+\psi)$ threshold.

for the polygon shape. These values are summarized in Table II. Triacontakaidigon 11 was too small to be measured. For circles $\oslash>1 \mu \mathrm{m}$, measured values differ from specified values on the order of $1 \%$.

We studied if the threshold $\theta=0.5$ is still applicable if a sphere is slightly out of visual focus. Figure 10 shows four images of a $5 \mu \mathrm{m}$ glass microsphere (Structure Probe, Inc., West Chester, PA), recorded with a CCD camera through our optical system. Figure 10(c) is in visual focus. Figure 10(b) and (d) were taken $2 \mu \mathrm{m}$ proximal and $2 \mu \mathrm{m}$ distal to the focus, respectively. Figure 10(a) was taken $4 \mu \mathrm{m}$ proximal to focus. The same threshold, determined from the median background value and the darkest bubble wall values, was applied to all four of the images. From each binary-segmented image, the size of an enclosed area representing a sphere was measured. From this area the microsphere diameter was calculated. The diameters calculated from Figure 10(b) and (c) were $5.01 \mu \mathrm{m}$; the diameter calculated from Figure 10(d) was $4.95 \mu \mathrm{m}$. The diameter could not be calculated from Figure 10(a), which was too far out of focus. Based on these measurements with calibration spheres, we assume that diameters from bubbles that were slightly out of focus could be correctly measured with the threshold used. 


\begin{tabular}{ccc}
\hline Triacontakaidigon & $\begin{array}{c}\text { Specified } \\
\text { diameter } \\
(\mu \mathrm{m})\end{array}$ & $\begin{array}{c}\text { Measured } \\
\text { diameter } \\
(\mu \mathrm{m})\end{array}$ \\
\hline 1 & $10.0 \pm 0.1$ & 10.03 \\
2 & $5.0 \pm 0.1$ & 5.06 \\
3 & $3.0 \pm 0.1$ & 3.02 \\
4 & $2.0 \pm 0.1$ & 1.99 \\
5 & $5.0 \pm 0.1$ & 5.06 \\
6 & $3.0 \pm 0.1$ & 3.03 \\
7 & $2.0 \pm 0.1$ & 1.99 \\
8 & $1.6 \pm 0.1$ & 1.60 \\
9 & $1.0 \pm 0.1$ & 0.96 \\
10 & $0.8 \pm 0.1$ & 0.66 \\
11 & $0.4 \pm 0.1$ & -
\end{tabular}

Table II: Specified and measured diameters of triacontakaidigons.

Characteristic aberration was observed when a large part of the bubble was between focal plane and objective lens, as demonstrated in the next two figures. Figure 11 shows optical images of highly stable Quantison $^{\mathrm{TM}}$ (Upperton Limited) UCA microbubbles placed underneath a glass coverslip and shifted through the visual focus of our optical system. Each frame corresponds to a $43 \times 32 \mu \mathrm{m}^{2}$ area. Figure 11 (e) is in visual focus. The bubbles that were below the focal plane got fuzzy rims [Figure 11(g), (h), (i)], whereas bubbles largely above the focal plane got bright centers with optical interference patterns around them [Figure 11(a) and (b)]. Figure 12 displays a collection of randomly taken pictures of freely flowing, ultrasound insonified, experimental UCA microbubbles. Figure 12(a) and (f) contain bubbles with a bright center, which are considered to be out of focus, and some sharp bubbles in the lower part of the frames. Figure 12(b), (c), (d), and (e) contain both sharp and fuzzy, unsharp bubbles that are comparable in size. Bubbles that were clearly out of focus were not taken into account in this study.

We quantified the errors caused by our optical recording system and our segmentation procedure [37]. The precision of the bubble diameter measurement is dependant of axial focus deviation of the bubble, light intensity, uniformity of illumination, CCD channel, multichannel plate amplification, and choice of region of interest. Because the choice of the region of interest is directly related to the threshold to be used, we do not have to consider this error separately. As we demonstrated with the two-dimensional simulations, a slightly changed threshold value from the $50 \%$ level between object and background intensity will not cause a systematic error. Because we only measured bubbles that were in visual focus, 


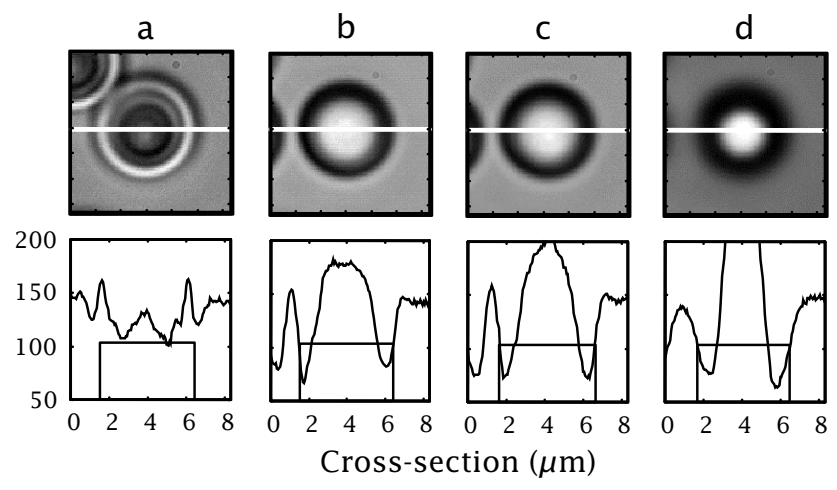

Figure 10: Intensity cross-sections of a $5 \mu \mathrm{m}$ glass calibration particle, $4 \mu \mathrm{m}$ proximal to focus (a), $2 \mu \mathrm{m}$ proximal to focus (b), in focus (c), and $2 \mu \mathrm{m}$ distal to focus (d).

and we found no error from spheres that were slightly out of focus, the error caused by defocusing is considered negligible for our measurements. The random error, caused by light intensity, uniformity of illumination, CCD channel, and multichannel plate amplification, was calculated from 184 separate measurements of bubble diameters from 21 different bubbles on image sequences of freely flowing experimental UCA and freely flowing gas bubbles. The bubbles were in visual focus. They were not insonified with ultrasound. Their diameters ranged from $1.4 \mu \mathrm{m}$ to $28 \mu \mathrm{m}$. The gain of each CCD was varied, as was the exposure time, resulting in different illumination per frame. In each frame, the same region of interest was selected. For each bubble, the mean diameter was calculated. The largest and the smallest diameter measured were used to calculate the maximal deviation from the mean diameter due to random error. The maximal deviations are plotted in [Figure 13] as a function of the mean bubble diameter measurements. The figure shows that the values of the random error do not exceed $9 \%$ of the mean diameter. 


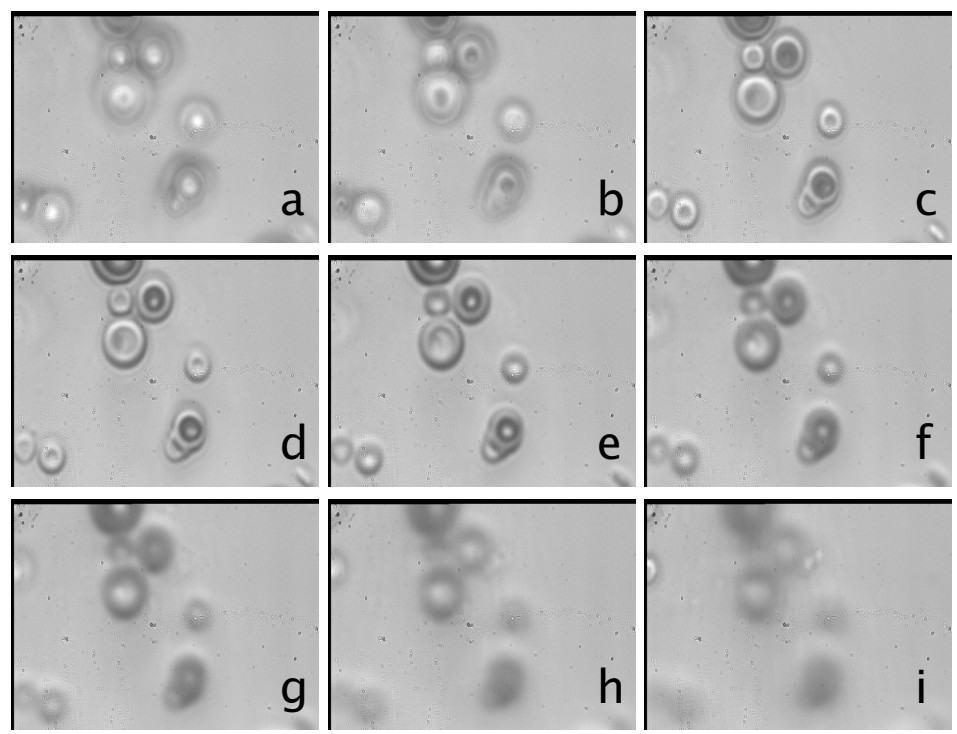

Figure 11: Quantison ${ }^{\mathrm{TM}}$ contrast microbubbles above the focal plane of the optical system (a)-(d), shifted through visual focus (e), below the focal plane (f)-(i). Each frame corresponds to a $43 \times 32 \mu \mathrm{m}^{2}$ area.

\section{Insonified UCA measurements}

In this study, 583 results of initial diameter and maximal diameter measurements of insonified bubbles, selected from 1320 events, were subjected to an exhaustive analysis. Peak negative acoustic pressures applied to these bubbles ranged from 0.06 $\mathrm{MPa}$ to 0.85 $\mathrm{MPa}$. Bubble diameters were measured, using the $50 \%$ threshold between darkest foreground and median background, as described in the previous section. Figure 14 summarizes the data from events at four different acoustic pressures, corresponding to mechanical indices of $\mathrm{MI}=0.089, \mathrm{MI}=0.15, \mathrm{MI}=0.25$, and $\mathrm{MI}=0.39$. Maximal diameters were plotted as a function of initial bubble diameters. As Figure 14 shows, the bubbles investigated had initial diameters ranging from $1 \mu \mathrm{m}$ to $4 \mu \mathrm{m}$. We found no observations for initial diameters larger than $3 \mu \mathrm{m}$ at $\mathrm{MI}=0.25$ [Figure 14(c)] and at $\mathrm{MI}=0.39$ [Figure 14(d)], in contrast to the observations at $\mathrm{MI}=0.089[$ Figure 14(a)] and at $\mathrm{MI}=0.15$ [Figure 14(b)]. The resonance size corresponding to the scanning frequency used, is estimated from theory [38] at $13.4 \mu \mathrm{m}$. Therefore, the range of sizes studied is mainly located in the acoustic Rayleigh scattering zone. This is clearly shown in Figure 14, in which 


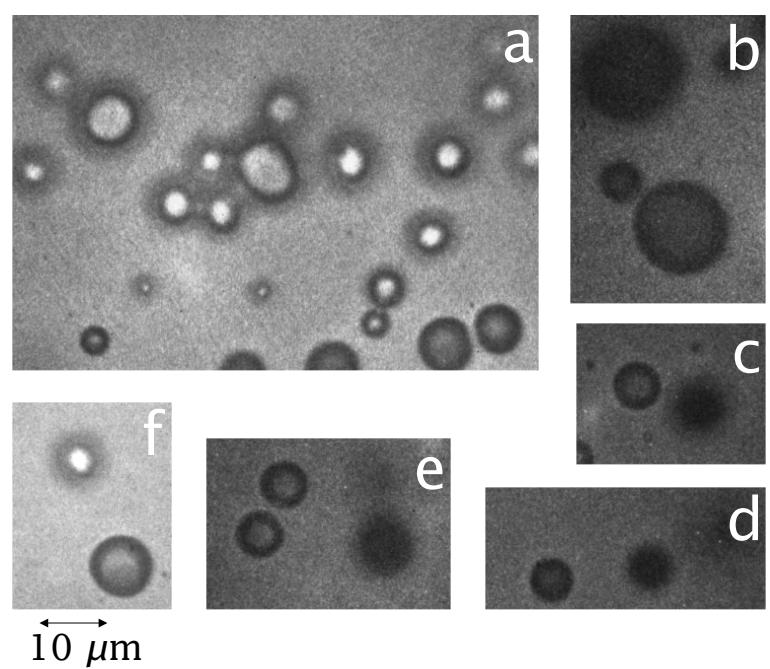

Figure 12: Randomly taken pictures of freely flowing, ultrasound insonified, experimental UCA. Bubbles with a bright center are considered to be out of focus (a), (f). Sharp and unsharp, fuzzy bubbles are comparable in size (b)-(e)

the maximal bubble expansion increases for larger bubbles, especially at the lowest acoustic pressure applied. At higher pressures, the slope of increase in bubble expansion as a function of initial diameter is steeper. This demonstrates that bubbles at these pressures undergo strong nonlinear oscillations. In addition, we can appreciate for all acoustic pressures applied that bubbles with the same initial diameter can oscillate differently, leading to different maximal expansions. This phenomenon is more pronounced at higher acoustic pressures. At $\mathrm{MI}=0.15,15$ microbubbles in the range $2.8 \mu \mathrm{m}$ to $3.2 \mu \mathrm{m}$ reached maximal diameters between $3.2 \mu \mathrm{m}$ and $7.6 \mu \mathrm{m}$. This corresponds to a maximal difference in excursion of $\Psi=151 \%$. At $\mathrm{MI}=0.25$ we observed 25 microbubbles in the range $1.8 \mu \mathrm{m}$ to $2.2 \mu \mathrm{m}$ expand to maximal diameters between $2.5 \mu \mathrm{m}$ and $8.8 \mu \mathrm{m}$, corresponding to $\Psi=340 \%$.

To further explore these large differences in maximal expansion, we investigated the bubble response at high MI. An example of this investigation is demonstrated in Figure 15, in which three identical UCA bubbles expanded to different maximal diameters. Each frame corresponds to a $55 \times 45 \mu \mathrm{m}^{2}$ area. Figure 15(a) was taken before ultrasound arrival. The maximal difference in excursion is $\Psi=28 \%$.

Figure 16 summarizes the results of 39 bubbles selected from ten events, recorded at an MI of 0.93. Figure 16 displays the relative bubble excursion as a function of the initial diameter. Identical markers indicate bubbles from the same sequence. In each first frame of the image sequences, bubbles of apparently the same size could be observed. Hence, for these bubbles, all conditions such as illumination, gain, and 


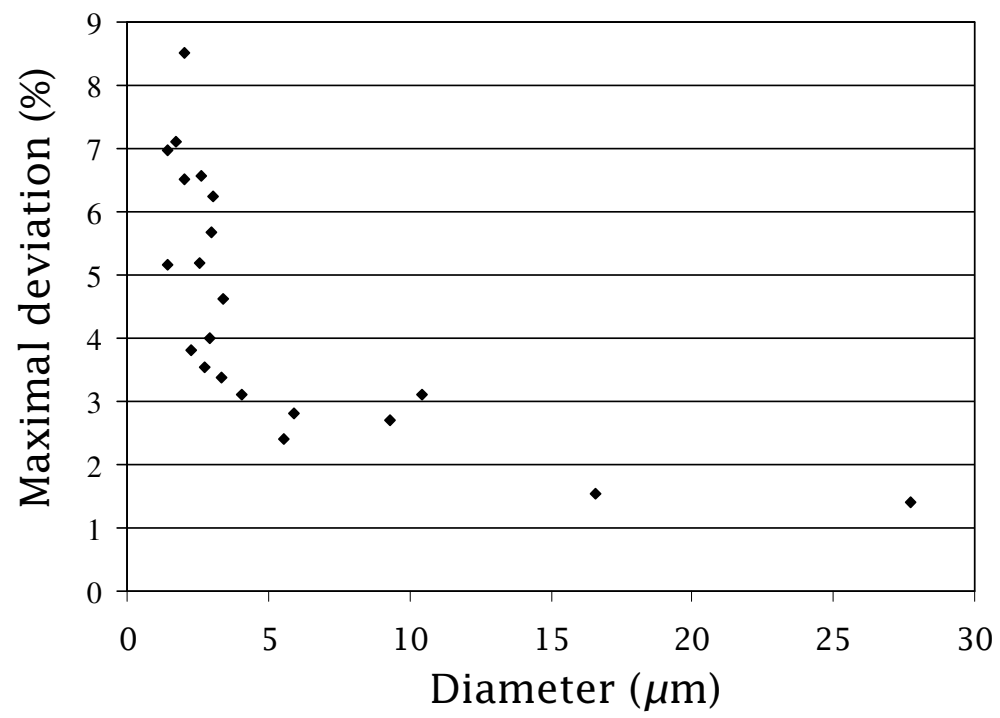

Figure 13: Maximal deviation in bubble measurement due to random error caused by the optical system and the segmentation process, as a function of mean bubble diameter measurement.

ultrasound field were kept unchanged, and the previously calculated random errors do not apply. We clearly notice that bubbles recorded from the same events (e.g., those indicated by ' $*$ ') oscillate differently. All these bubbles had initial diameters approaching $2.6 \mu \mathrm{m}$, whereas their maximal diameters range from $5.0 \mu \mathrm{m}$ to $7.6 \mu \mathrm{m}$, corresponding to relative expansions of $91 \%$ to $185 \%$ ( $\Psi=94 \%$ ). Differences in oscillation or behavior of bubbles with similar initial sizes are also demonstrated in the optical images shown in Figure 17, which demonstrates bubble expansion and collapse at $\mathrm{MI}=1.2$. Each frame corresponds to a $88 \times 58 \mu \mathrm{m}^{2}$ area. In the first frame, taken before ultrasound arrival, no bubbles were visible. We presume that the bubbles were too small (i.e. below the optical resolution $\mathcal{R}$ ) to be detected. From Figure 17(b), (c), (d), and (e), the bubbles oscillate and appear to have similar sizes. Both bubbles expanded to $\oslash 17.0 \mu \mathrm{m}$ in Figure 17(d). In Figure 17(f), where the contraction phase of the ultrasonic wave starts, one bubble clearly collapsed while the other bubble continues contracting. In the last two frames, contraction is maximal, so both bubbles were no longer visible.

At acoustic pressures corresponding to $\mathrm{MI}>0.5$, not only the phenomenon of bubbles violently collapsing [39], but also the phenomenon of bubbles coalescing was observed [40]. Figure 18 was recorded during insonification at $\mathrm{MI}=0.93$. In each $88 \times 58 \mu \mathrm{m}^{2}$ frame, a $21 \times 22 \mu \mathrm{m}^{2}$ region of interest is 


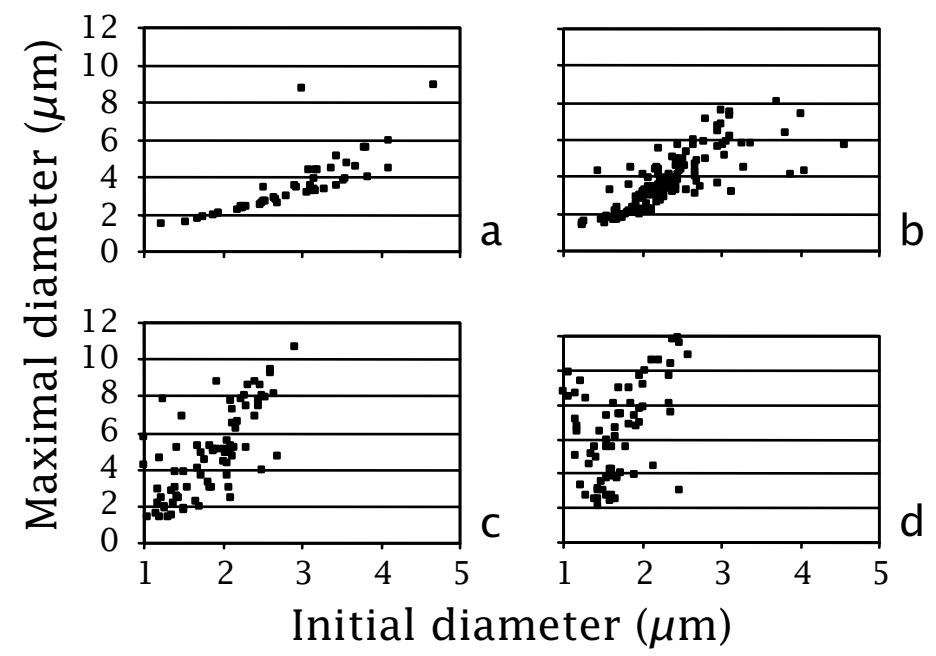

Figure 14: Bubble expansion at four different acoustic pressures. $\mathrm{MI}=0.089$ (a), $\mathrm{MI}=0.15$ (b), $\mathrm{MI}=0.25$ (c), MI $=0.39(d)$.

highlighted. In Figure 18(a) three sharp microbubbles can be discriminated, of which two seem to stick together. In Figure 18(b) there are only two separate expanding bubbles left. Figure 18(c) shows these two bubbles attaching. In Figure 18(d) the lower left bubble appears to merge into the upper right bubble. The remaining bubble appears to have an oval shape in Figure 18(e), but a round shape in the remaining frames. Such asymmetric oscillations were regularly observed at high acoustic pressures.

Mean relative bubble excursion is plotted as a function of acoustic pressure in Figure 19, from 134 bubbles with diameters between $1.8 \mu \mathrm{m}$ and $2.2 \mu \mathrm{m}$. Standard deviations of the data were calculated for each acoustic pressure. The plotted theoretical curves were calculated numerically for a $\oslash 2 \mu \mathrm{m}$ bubble and based on the parameters of the constant thickness model [34]. The models used are based on a modified RPNNP equation, named after its developers Rayleigh, Plesset, Noltingk, Neppiras, and Poritsky [41], and a modified Herring equation [38]. We refer to these models as model A and model $\mathrm{B}$, respectively. At acoustic pressures below $0.4 \mathrm{MPa}$, model $\mathrm{B}$ comes closest in describing the mean expansion, although there is clearly no fit. For higher acoustic pressures, model B predicts values much higher than the measured ones. 


\section{DisCUSSION AND CONCLUSIONS}

This was the first optical investigation of a large UCA data set using a $500 \mathrm{kHz}$ transducer. The errors caused by our optical system and segmentation process are within $9 \%$ of the mean bubble sizes measured for median UCA bubble diameters larger than $1.4 \mu \mathrm{m}$.

The initial diameters of the bubbles shown in Figure 14 are clearly not normally distributed. This is attributed to the lack of expansion of bubbles smaller than $2 \mu \mathrm{m}$ at lower pressures and to the rupturing and coalescing behavior of larger bubbles at higher pressures. Because only bubbles with measurable maxima were plotted, these two groups were excluded.

We checked the representativity of the bubbles analyzed for the whole agent by comparing the optically determined size distribution of our bubbles with published data of a SonoVue ${ }^{\mathrm{TM}}$ (Bracco Research SA, Geneva, Switzerland) distribution measured with a Coulter instrument [42]. The median diameter of $2 \mu \mathrm{m}$ is confirmed by these measurements, but bubbles over $4 \mu \mathrm{m}$ are hardly observed in the optical data. Only

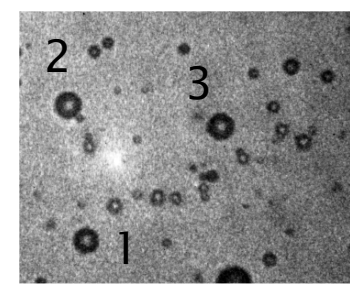

a

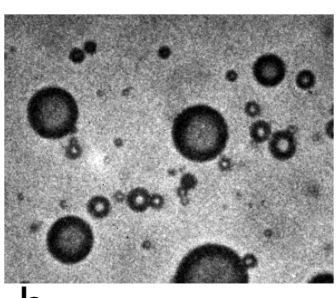

b

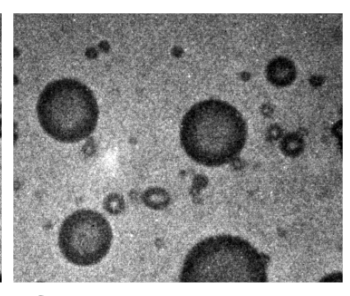

C

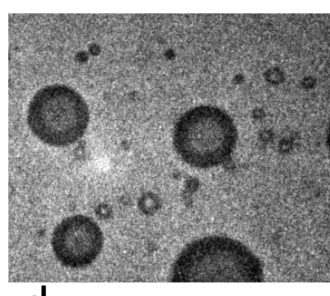

d

Figure 15: Optical image sequence of three microbubbles with apparently the same initial diameters, insonified at MI $=0.93$. Each frame corresponds to a $55 \times 45 \mu \mathrm{m}^{2}$ area. Frame (a) was taken before ultrasound arrival. The microbubbles expanded to different maximal diameters (b)-(d). 


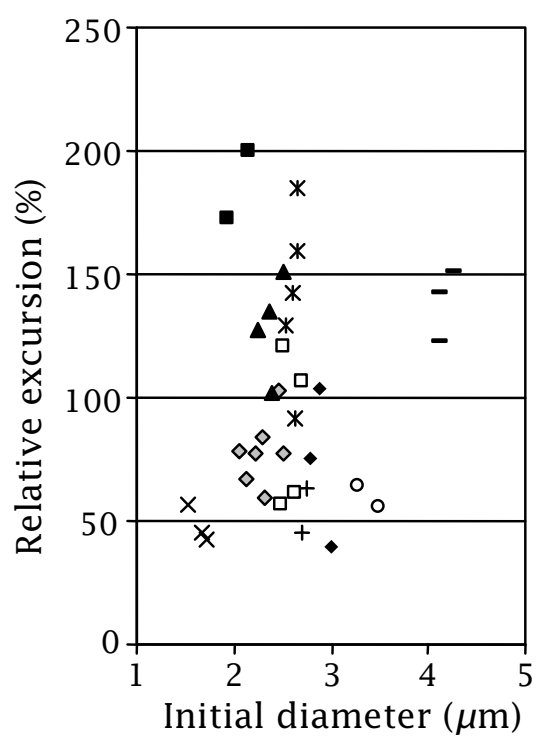

Figure 16: Relative excursion at $\mathrm{MI}=$ 0.93. 39 bubbles were selected from 10 image sequences. Identical markers indicate bubbles from the same image sequence.

bubbles showing expansion were measured. We conclude that our optical observations are representative in the diameter range $1 \mu \mathrm{m}$ to $4 \mu \mathrm{m}$.

Because the image exposure times are low relative to the interframe times, the measured maxima do not have to correspond to the true maximal bubble expansions. In worst case, if the bubble expands according to a sine, the maximal growth measured can be off the true value by half an interframing interval, which equals a twelfth of an expansion cycle, giving a measured excursion of $100 \% \times \cos (2 \pi / 12)=87 \%$ of the true excursion.

Because the bubbles in the experiments shown in Figure 15 are closer to each other than $1 \%$ of the acoustic wavelength, acoustic differences due to location are negligible in this situation.

Although big bubbles that are out of optical focus might cause differences in bubble oscillating behavior, we did not take such effects into account.

From the above results, it is concluded that identical bubbles can have different oscillating behavior. The differences in the oscillation maxima observed might be explained by differences in elastic properties 
of individual bubbles.

\section{ACKNOWLEDGMENTS}

We thank Martijn Frijlink for designing the calibration grid and Leo Bekkering for building part of the experimental setup.

\section{REFERENCES}

[1] H. Becher and P. N. Burns, Handbook of Contrast Echocardiography: LV Function and Myocardial Perfusion. Berlin: Springer-Verlag, 2000.

[2] P. N. Burns, P. Hilpert, and B. B. Goldberg, "Intravenous contrast agent for ultrasound Doppler: In vivo measurement of small tumor vessel dose-response," Proc. Annu. Int. Conf. IEEE Eng. Med. Biol. Soc., vol. 12, no. 1, pp. 322-324, 1990.

[3] N. de Jong, A. Bouakaz, and F. ten Cate, "Ultrasound contrast imaging: principles and applications," Klinische Fysica, vol. /3, pp. 24-31, 2000

[4] N. de Jong and F. J. Ten Cate, "New ultrasound contrast agents and technological innovations," Ultrasonics, vol. 34, pp. 587-590, 1996.

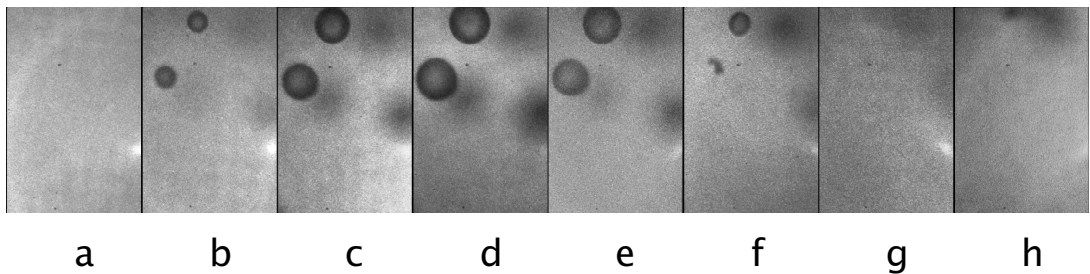

Figure 17: Bubble expansion (b)-(e) and collapse (f) within one acoustic cycle at MI $=1.2$. 


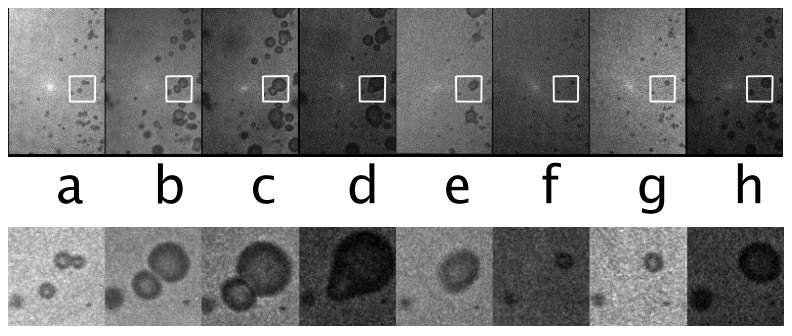

Figure 18: Bubbles coalescing during insonification at $\mathrm{MI}=0.93$.

[5] N. de Jong, P. J. A. Frinking, A. Bouakaz, and F. J. Ten Cate, "Detection procedures of ultrasound contrast agents," Ultrasonics, vol. 38, pp. 87-92, 2000.

[6] N. de Jong, A. Bouakaz, P. J. A. Frinking, and F. J. Ten Cate, "Contrast-specific imaging methods," in Ultrasound Contrast Agents. Basic principles and clinical applications, 2nd ed., B. Goldberg, J. Raichlen, and F. Forsberg, Eds. London: Martin Dunitz Ltd, 2001, pp. 25-36.

[7] N. de Jong, L. Hoff, T. Skotland, and N. Bom, "Absorption and scatter of encapsulated gas filled microspheres: theoretical considerations and some measurements," Ultrasonics, vol. 30, no. 2, pp. 95-103, 1992.

[8] N. de Jong and L. Hoff, "Ultrasound scattering properties of Albunex microspheres," Ultrasonics, vol. 31, no. 3, pp. 175-181, 1993.

[9] C. C. Church, "The effects of an elastic solid surface layer on the radial pulsations of gas bubbles," J. Acoust. Soc. Am., vol. 97, no. 3, pp. 1510-1521, 1995.

[10] L. Hoff, “Acoustic properties of ultrasonic contrast agents," Ultrasonics, vol. 34, pp. 591-593, 1996.

[11] P. J. A. Frinking and N. de Jong, "Acoustic modeling of shell-encapsulated gas bubbles," Ultrasound Med. Biol., vol. 24, no. 4, pp. 523-533, 1998.

[12] A. L. Klibanov, K. W. Ferrara, M. S. Hughes, J. H. Wible Jr., J. K. Wojdyla, P. A. Dayton, K. E. Morgan, and G. H. Brandenburger, "Direct video-microscopic observation of the dynamic effects of medical ultrasound on ultrasound contrast microspheres," Invest. Radiol., vol. 33, no. 12, pp. 863-870, 1998.

[13] P. Dayton, K. Morgan, M. Allietta, A. Klibanov, G. Brandenburger, and K. Ferrara, "Simultaneous optical and acoustical 


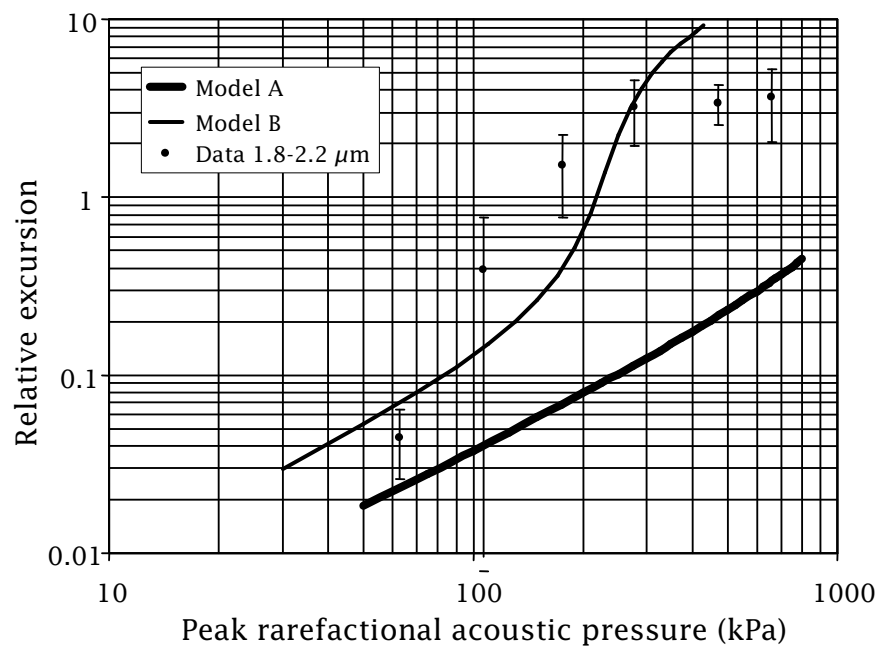

Figure 19: Mean relative excursion as a function of acoustic pressure applied, for bubble diameters ranging from $1.8 \mu \mathrm{m}$ to $2.2 \mu \mathrm{m}$, compared to model $\mathrm{A}$ and model $\mathrm{B}$.

observations of contrast agents," Proc. IEEE Ultrason. Symp., pp. 1583-1591, 1997.

[14] P. A. Dayton, K. E. Morgan, A. L. Klibanov, G. H. Brandenburger, and K. W. Ferrara, "Optical and acoustical observations of the effects of ultrasound on contrast agents," IEEE Trans. Ultrason., Ferroelect., Freq. Contr., vol. 46, no. 1, pp. 220-232, 1999.

[15] Y. Takeuchi, "Pulsed stroboscopic visualizer to synchronously monitor the microballoon under insonification," Proc. IEEE Ultrason. Symp., pp. 1645-1649, 1998.

[16] —, IEEE Trans. Ultrason., Ferroelect., Freq. Contr., vol. 46, no. 4, p. cover page, 1999.

[17] K. Kuribayashi, N. Kudo, M. Natori, and K. Yamamoto, "A high-magnification and high-speed system for the observation of microbubbles under ultrasound exposure," Proc. IEEE Ultrason. Symp., pp. 1755-1758, 1999.

[18] N. de Jong, P. J. A. Frinking, A. Bouakaz, M. Goorden, T. Schuurmans, X. Jingping, and F. Mastik, "Optical imaging of contrast agent microbubbles in an ultrasound field with a 100-MHz camera," Ultrasound Med. Biol., vol. 26, no. 3, pp. 487-492, 2000.

[19] K. E. Morgan, J. S. Allen, J. E. Chomas, P. A. Dayton, and K. W. Ferrara, "Experimental and theoretical analysis of individual contrast agent behavior," Proc. IEEE Ultrason. Symp., pp. 1685-1688, 1999.

[20] D. A. Agard, "Optical sectioning microscopy: Cellular architecture in three dimensions," Annu. Rev. Biophys. Bioeng., vol. 13, pp. 191-219, 1984. 
[21] A. K. Jain, Fundamentals of Digital Image Processing. Englewood-Cliffs: Prentice-Hall, 1989.

[22] I. T. Young, "Quantitative microscopy,” IEEE Eng. Med. Biol., vol. 15, no. 1, pp. 59-66, 1996.

[23] H. C. Lee, "Review of image-blur models in a photographic system using the priciples of optics," Opt. Eng., vol. 29, no. 5, pp. 405-421, 1990.

[24] Lord Rayleigh, "Investigations in optics, with special reference to the spectroscope," Philos. Mag., vol. 8, no. 49, pp. 261-274, 1879.

[25] P. A. Stokseth, "Properties of a defocused optical system," J. Opt. Soc. Am., vol. 59, no. 10, pp. 1314-1321, 1969.

[26] S. F. Gibson and F. Lanni, "Experimental test of an analytical model of aberration in an oil-immersion objective lens used in three-dimensional light microscopy," J. Opt. Soc. Am. A, vol. 8, pp. 1601-1613, 1991.

[27] G. Rönneberg, "Eignung von Fokusverfahren für Beobachtung und Vermessung von Mikrostrukturen,” Darmstadt: Institut für EMK, Tech. Rep., 1996.

[28] N. Dey, A. Boucher, and M. Thonnat, "Modélisation et étude de la formation de l'image d'un objet 3D translucide," Presented at: 2ème colloque francophone Méthodes et Techniques Optiques pour l'Industrie, 2001

[29] F. C. A. Groen, I. T. Young, and G. Ligthart, "A comparison of different focus functions for use in autofocus algorithms," Cytometry, vol. 6, pp. 81-91, 1985.

[30] C. Preza, M. I. Miller, L. W. Thomas Jr., and J. G. McNally, "Regularized linear method for reconstruction of threedimensional microscopic objects from optical sections," J. Opt. Soc. Am. A, vol. 9, no. 2, pp. 219-228, 1992.

[31] F. R. Boddeke, L. J. van Vliet, H. Netten, and I. T. Young, "Autofocusing in microscopy based on the OTF and the sampling," BioImaging, vol. 2, pp. 193-203, 1994.

[32] Z. Kam, B. Hanser, M. G. L. Gustafsson, D. A. Agard, and J. W. Sedat, "Computational adaptive optics for live threedimensional biological imaging," Proc. Natl. Acad. Sci. USA, vol. 98, pp. 3790-3795, 2001.

[33] D. G. Flagello, T. Milster, and A. E. Rosenbluth, "Theory of high-NA imaging in homogeneous thin films," J. Opt. Soc. Am. A, vol. 13, no. 1, pp. 53-64, 1996.

[34] J. M. Gorce, M. Arditi, and M. Schneider, "Influence of bubble size distribution on the echogenicity of ultrasound contrast agents: A study of SonoVue ${ }^{\mathrm{TM}}$," Invest. Radiol., vol. 35, no. 11, pp. 661-671, 2000.

[35] B. Matérn, "Precision of area estimation: a numerical study," J. Microsc., vol. 153, no. 3, pp. 269-284, 1989.

[36] M. Postema, A. Bouakaz, C. T. Chin, and N. de Jong, "Real-time optical imaging of individual microbubbles in an ultrasonic field," Proc. IEEE Ultrason. Symp., pp. 1679-1682, 2001.

[37] G. L. Squires, Practical physics, 3rd ed. Cambridge: Cambridge University Press, 1989.

[38] K. E. Morgan, J. S. Allen, P. A. Dayton, J. E. Chomas, A. L. Klibanov, and K. W. Ferrara, "Experimental and theoretical evaluation of microbubble behavior: Effect of transmitted phase and bubble size," IEEE Trans. Ultrason., Ferroelect., Freq. Contr., vol. 47, no. 6, pp. 1494-1509, 2000.

[39] M. Postema, A. Bouakaz, and N. de Jong, IEEE Trans. Ultrason., Ferroelect., Freq. Contr., vol. 49(3), p. cover page, 2002.

[40] M. Postema, A. Bouakaz, C. T. Chin, and N. de Jong, "Optically observed microbubble coalescence and collapse," Proc. IEEE Ultrason. Symp., pp. 1900-1903, 2002.

[41] N. de Jong, R. Cornet, and C. T. Lancée, "Higher harmonics of vibrating gas-filled microspheres. Part one: simulations," Ultrasonics, vol. 32, no. 6, pp. 447-453, 1994.

[42] M. Schneider, M. Arditi, M. B. Barrau, J. Brochot, A. Broillet, R. Ventrone, and F. Yan, "BR1: A new ultrasonographic contrast agent based on sulfur hexafluoride-filled microbubbles," Invest. Radiol., vol. 30, no. 8, pp. 451-457, 1995. 